\title{
Characterizing Electrical Output of Bifacial Photovoltaic Modules by Altering Reflective Materials
}

\author{
Steven Sciara, Sung Joon Suk*, George Ford \\ Department of Construction Management, Western Carolina University, Cullowhee, NC, USA \\ Email: sasciara@email.wcu.edu, "sungjoon@wcu.edu,gford@email.wcu.edu
}

Received 7 February 2016; accepted 6 March 2016; published 9 March 2016

Copyright (C) 2016 by authors and Scientific Research Publishing Inc.

This work is licensed under the Creative Commons Attribution International License (CC BY).

http://creativecommons.org/licenses/by/4.0/

(c) (i) 0 pen Access

\begin{abstract}
Bifacial photovoltaic (PV) modules offer potentially enhanced power output over conventional modules due to their reported ability to harvest reflected radiation, increasing output up to an additional $30 \%$. However, this enhancement has yet to be confirmed in the literature. This paper reports on a study comparing the power output of two nominally identical $700 \mathrm{~W}$ photovoltaic arrays utilizing equivalent system components and data logging equipment with varying configurations of reflecting geometries and materials. This study was undertaken at the Appalachian State University Solar Research Laboratory in Boone, NC, which houses two Class 1 pyranometers and pyrheliometer. PV power was reported under well-quantified irradiance conditions, including direct beam fraction. Six trials over six months (November-April) with varying reflective materials and geometries revealed that different reflecting materials did not significantly change power output. Mounting an array at $0^{\circ}$ did adversely affect power output compared to the array at a $36^{\circ}$ angle relative to horizontal using the same reflective material. Additional studies with varied materials, panel locations and geometries different from those tested may improve the power output.
\end{abstract}

\section{Keywords}

Photovoltaic, Bifacial Photovoltaic, Solar Energy, Electrical Output

\section{Introduction}

The recent introduction of bifacial photovoltaic (PV) modules to the retail market suggests the need to investigate types of locations in which they may be installed in order to obtain the best performance possible based on

"Corresponding author.

How to cite this paper: Sciara, S., Suk, S.J. and Ford, G. (2016) Characterizing Electrical Output of Bifacial Photovoltaic Modules by Altering Reflective Materials. Journal of Building Construction and Planning Research, 4, 41-55. 
their unique design. Double modules utilize the upper and lower faces of the module to generate electrical power. A wattage increase of up to $30 \%$ may be realized by properly installing the modules in locations where light may reach the lower face of the module [1]. The additional power produced is determined by module orientation relative to a reflecting surface, geographic location, installation techniques, shadows produced by the grid system holding the modules, weather, and reflective properties of the varied surfaces below the modules. However, limited independent research has been conducted to verify the performance of bifacial PV modules due to limited adoption of this type of product, as well as inconsistencies in estimated predicted increases in power output.

This study provides a comparison of power output of two arrays consisting of bifacial PV modules. The testing of reflective materials as well as a change in geometry of the modules characterizes electrical output. The output of Sanyo Heterojunction with Intrinsic Thin Layer (HIT) 195 Double Bifacial Photovoltaic (PV) Modules is assessed at Appalachian State University in Boone, NC when various materials are placed below the modules along with different geometries. Sanyo/Panasonic bifacial panels were chosen for this study due to the limited number of bifacial panels currently available on the market.

\section{Literature Review}

\subsection{Structure and Functionality of Sanyo HIT Bifacial PV Modules}

PV cell performance continues to improve with technology. PV cells are currently capable of maintaining a 19.5\% efficiency level [2]. Depending on the manufacturer, the type and quality of the cell, and its age, this percentage may increase or decrease. Most cells are tested in a laboratory where certain conditions are constant, permitting the manufacturer to make claims about their performance. The Sanyo HIT 195 Double Bifacial Modules have a cell efficiency of $19.3 \%$ in a laboratory setting [3], but this percentage varies depending on their location and installation.

The Sanyo HIT 195 Double Bifacial Photovoltaic Module attempts to produce higher power output per area by use of both top and bottom surfaces of the module. The modules may be installed at nearly any angle, but similar positioning to other PV modules would be most effective in an application with solar tracking and a lower opposing surface white in color or some other type of reflective material. The modules are designed to allow a small percentage of light transmittance to assist with lower module surface absorption and to create an aesthetically pleasing detail for canopy installations. The area below the module remains partially illuminated by light transmittance through the clear glass to assist in producing power [1], but the majority of the light is absorbed by the upper cells where most of the power is generated.

Traditionally, PV module performance is reported under Standard Test Conditions (STC) $\left(\mathrm{I}=1000 \mathrm{~W} / \mathrm{m}^{2}\right.$, Temp $=25^{\circ} \mathrm{C}$ ), but STC do not factor in nearby reflecting surfaces or their orientation. For purposes of clarity, STC are defined as: The most common and internationally accepted set of reference conditions, and rates module performance at a solar irradiance of $1000 \mathrm{~W} / \mathrm{m}^{2}$, spectral conditions of AM1.5, and a cell temperature of $25^{\circ} \mathrm{C}\left(77^{\circ} \mathrm{F}\right)$, [4]. Therefore, bifacial manufacturers report front-side performance only under STC in laboratory conditions, and additionally report a range of possible power enhancements produced under certain circumstances. This accounts for the HIT 195 Double Module rating of 195 watts, but an additional 30\%, or a maximum of 54 additional watts, may be produced by the lower cell surface for a total output of 249 watts per module [3].

The main element used for a solar module semiconductor is silicon. N-type (free electrons) silicon has had phosphorous added to it while a p-type (electron voids) silicon has had boron added [5]. A conventional solar cell consists of minimal layers: an electrode, glass with an anti-reflective layer, n-type, p-type, crystalline $\mathrm{Si}$, and a metal electrode (Figure 1).

Sanyo HIT 195 Bifacial Modules combine the use of single crystalline silicon (Si) with extremely thin amorphous silicon layers (a-Si) on both sides of the cell to allow both the front and back side of the photovoltaic module to absorb light and produce energy. Heterojunction with Intrinsic Thin Layer (HIT) modules have high conversion efficiency, excellent temperature characteristics, and a considerable output under diffuse and low light conditions [1].

By contrast, the HIT Double Module has many layers: a top electrode, p-type amorphous Si, intrinsic amorphous $\mathrm{Si}$, crystalline Si (n-type), another layer of intrinsic amorphous $\mathrm{Si}$, intrinsic amorphous $\mathrm{Si}$, n-type amorphous $\mathrm{Si}$, and a bottom electrode. This multi-layering effect allows light absorption from both sides. Compared with conventional solar cells, HIT solar cells (Figure 2) have a better temperature coefficient and a higher-open circuit voltage [7]. 

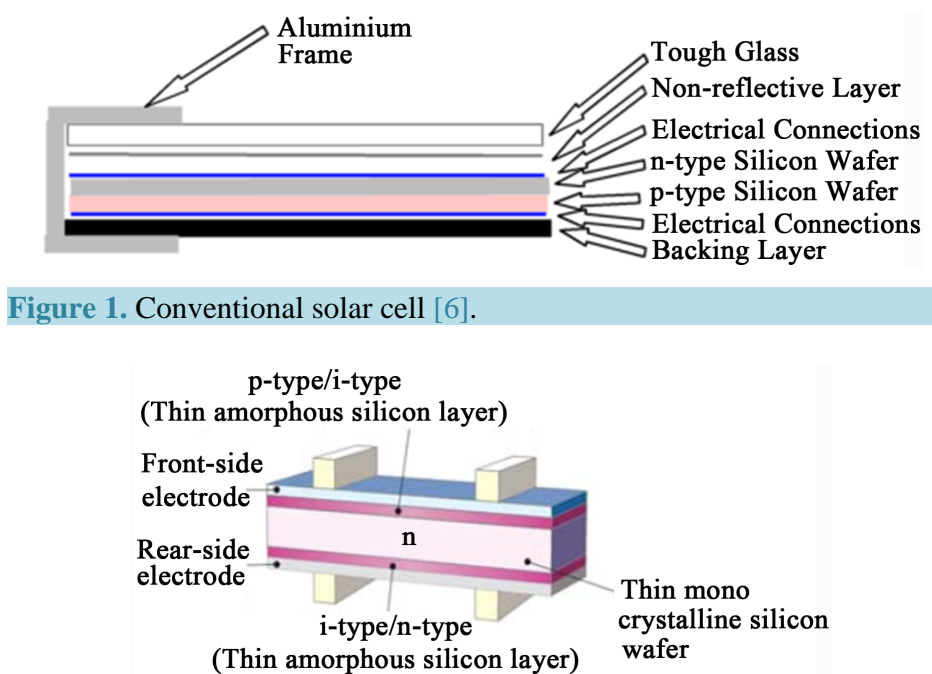

Figure 2. Sanyo HIT solar cell [1].

SANYO North America Corporation (SANYO), a subsidiary of SANYO Electric Co., Ltd., announced that as of April 1, 2012, the branding of its HIT $^{\circledR *}$ solar modules, would change from "SANYO” to "Panasonic", [8].

\subsection{Power vs. Size of HIT Modules}

Bifacial modules are designed for optimal performance with minimal space and are available in different power outputs, depending on the application. A Sanyo HIT 215 Monofacial Module physically, is 13.53 square feet with an STC rating of 215 watts, compared to a Sanyo HIT 195 Double Bifacial Module at 12.8 square feet, with an STC of 195 watts per module. For the bifacial module, the lower face cells may facilitate an increase in power to 249 watts in less surface area than the monofacial modules [3]. By calculating the power output of a series of ten modules, Sanyo Bifacial modules would consume 7.3 fewer square feet than Sanyo Monofacial modules, but at Bifacial maximum rated efficiency, may possibly produce an additional 340 watts.

\subsection{Experimental Applications of Bifacial Modules}

Although research on bifacial photovoltaic modules began in the early 1960s, Sanyo Electric Co., Ltd. developed and trademarked the HIT Double Modules in 2010 [1]. Their primary use has been in canopies and solar screening applications to capture energy and to help reduce solar gain indoors in the summer. They may also be installed in ballast mounts or on vertical walls.

An experimental study done in the Czech Republic with bifacial photovoltaic modules found that they collected $72 \%$ more energy than monofacial modules [9]. In other experimental studies, findings revealed that "the increase in power conversion density that is achievable by using bifacial solar cells depends on the conversion efficiency of the cells under back illumination, which can be as high as 94 percent of the front efficiency, and on the amount of light that reaches the back surface" [10].

As of 2005, The European Photovoltaics Industrial Association determined that flat-panel crystalline silicon modules comprised $90 \%$ of photovoltaic devices produced. The Association estimated that cell efficiency would need to increase from $12 \%$ to $20 \%$ utilizing contacts on the back surface, regarded as back contact solar cell (BCSC), in an attempt to develop high-efficiency contacts. In addition to this modification, it was noted that development of bifacial cells with BCSC could drive down the cost of per peak watt (WP). This study, conducted with the use of a laminated grid of wire external busbars (LGWEB), in combination with bifacial Czochralski-grown silicon (Cz-Si), recommended this type of module could potentially produce an increase in efficiency exceeding 21\% [11]. The development of high-efficiency contacts on the back surface of the cell would reduce the amount of silicon used and reduce the production costs. In contrast, Development Status of High-Efficiency HIT Solar Cells, in a study, specifically noted that the Sanyo HIT Double Module is capable of producing 10.9\% more output than a single upper side HIT module. 
A hybrid solar thermal system using bifacial modules was tested using a transparent solar plane in the working spectral region of a PV module. A determination was made that a bifacial PV module could be used for solar thermal and that the bifacial module produced approximately $40 \%$ more electrical energy than the conventional PV modules [12].

Two case studies highlighted by Sanyo include the successful home, lumenHaus, built by Virginia Tech that won the Solar Decathlon 2010 in Europe, and a solar canopy installation on an office building in Atlanta. What is not stated in either of the two case studies is what material was used below the modules for the lumenHaus or for the surface below the canopy of the Atlanta office building [13]. DuROCKAlfacing International Manufacturing Company in Woodbridge, Ontario has mounted a $10 \mathrm{~kW}$ array of HIT 195 Double Modules at a $30^{\circ}$ angle on their flat roof (Figure 3). The reflective material used below the modules was TIOCOAT ${ }^{\mathrm{TM}}$, a white protective roofing material. The bifacial modules as reported produced between $195 \mathrm{~W}$ and $210 \mathrm{~W}$ [14].

Data were rather inconsistent, with few studies conducted to investigate the performance of bifacial modules. Sanyo Electric Corporation states that the HIT Double Modules are capable of producing power within their specifications. Each application and location will have a different effect on the module or series of modules.

The Institute for Solar Energy Research Hameln/Emmerthal (Institutfür Solarenergieforschung Hameln, ISFH) tested a white surface behind bifacial modules. They used the modules to shape the company acronym on the front of the building. Behind the bifacial modules, a white background was placed, capable of reflecting light onto the back surface of the module. The modules used were back-contacted bifacial solar cells (BACK OECO) produced experimentally by ISFH. The power output per cell was expected to be equivalent to that of at least a $30 \%$ efficient monofacial cell of the same size [15].

\subsection{Common Installation of Bifacial Photovoltaic Modules}

The most common installation of Sanyo Bifacial Modules is in the form of canopies that serve as covered walkways, carports, or porch roofs. Some applications use HIT Double Bifacial Modules for window screens (when angled appropriately), skylights, and in other atypical roof installations with reflective material below.

The manufacturer recommends the following possible applications: architectural applications, awnings, balconies, bus shelters, Building Integrated Photovoltaic (BIPV) arrays [8], deck and porch coverings, canopies, carports, facades, fences, siding, trellises or tracking systems [1].

The flexibility of applications introduces new options that permit HIT 195 Double Module integration into net energy producing architectural details not previously realized. In other installations, modules were placed in angled ballasted frames on flat rooftops with light or white roofing material below the lower surface [14].

Designers and architects seem to favor the aesthetic appearance of the HIT Bifacial Modules. The traditional monofacial modules are commonly installed on a roof, either flat or pitched. Bifacial modules may become a functioning portion of the architecture as well as an electric generating device by integrating them in interesting structures purposefully designed to withstand the weight and wind shear.

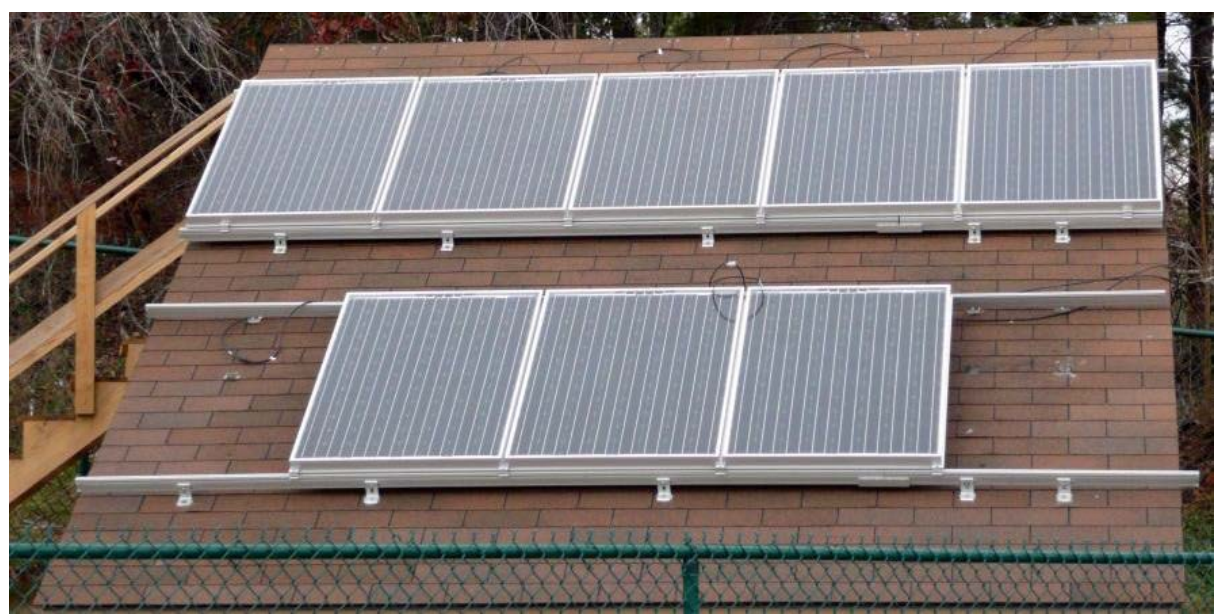

Figure 3. Photo of Trial 1. Upper array shingle flush 5 modules, lower array shingle flush 3 modules. (Refer to Table 1 for details). 


\section{Research Methods}

This study was conducted in Boone, NC at the Appalachian State University Solar Lab with coordinates of: latitude $36^{\circ} 12^{\prime} 24.53^{\prime \prime} \mathrm{N}$, longitude $81^{\circ} 39^{\prime} 18.79^{\prime \prime} \mathrm{W}$. The experimental design consisted of two nominally identical systems, each comprised of three Sanyo HIT 195 Double Bifacial Modules, a SMA Sunny Boy 700-US grid interactive inverter, and an Ohio Semitronics PC8-004-08X5 power transducers. The independent variable was three reflective materials, and the dependent variable, power, was recorded each minute during all the trials warranting six total planned trials. Two research grade pyranometers measured total global solar irradiance and a pyrheliometer measured the direct component of solar irradiance from the sun. Two Ohio Semitronics PC8004-08X5 transducers supplied the Campbell Scientific data logger to record results.

The modules were fastened to the aluminum frame at a distance of 6 inches from the roof surface. Each array functioned independently of one another, and had identical electrical components and wiring. Additionally, 12-2 with ground wiring from the inverter to the breaker panel was cut to the same length for both systems. Both arrays were mounted on the UNIRAC rail system with clips acquired from UNIRAC specifically used for these Sanyo modules.

At the top and the bottom of one module series string, approximately 8 inches of reflective material was extended beyond the aluminum framework. The reflective materials used on the roof surface were sized 69 inches high and 180 inches wide, which allowed an additional 40.5 inches of reflective material on the far left of the left array and 40.5 inches on the far right of the right array, and assisted in capturing the maximum reflectance as the sun rose and set. Additionally, there were 19.5 inches between the upper array and the lower array.

The modules were placed on a $36^{\circ}$ angle mock roof. Two arrays were mounted horizontally in a series with a positive terminal on the left of the array, and a negative terminal on the right. The two arrays were placed horizontally, one above the other, by use of UNIRAC aluminum racking. Each array consisted of three modules wired in series. The adjustable aluminum racking fastened to the mock roof held the modules parallel to the roof's surface or permitted the horizontal placement of the lower array. Varying reflective materials and geometries were purposefully used under two separate arrays in six trials in the same location for a period of nearly five months.

A different reflective material was placed on the roof surface directly below each series of three modules to help determine if reflectivity of one material produces a higher PV power output than another. Trials of three materials in different configurations were performed for a total of six sets of data. The modules were connected in two sets of three series using two Sunny Boy 700-US inverters. The Sanyo HIT 195 Double Bifacial Modules are manufacturer rated using STC at 195W with the potential of $249 \mathrm{~W}$ at maximum output. At maximum output, the inverter tied to three of these modules should be able to support $747 \mathrm{~W}$. A technician from SMA America, LLC specified the SB 700-US stating this inverter has a power flex override of $3 \%$ for a total capability of 721 $\mathrm{W}$. The possibility of three modules producing an excess of $721 \mathrm{~W}$ is negligible since conditions in Boone, NC would have to be nearly identical to the set of reference conditions as described above in STC. Conversely, the testing of reflective materials could have produced power at peak performance neighboring those specified by Sanyo Electric Corporation.

Installation of an aluminum rack for each series of modules, wiring, module mounts, inverters, transducers, and grid tying was completed prior to the commencement of data collection. With the use of a research grade pyranometer, the first set of data to be collected was direct radiation. Direct radiation is the solar radiation from the sun that reaches Earth's surface without scattering [8]. Since most photovoltaic modules' electrical outputs are rated by the peak sun conditions $\left(1000 \mathrm{~W} / \mathrm{m}^{2}\right)$, it is important to determine how may peak sun hours the module has received. Actual peak sun hours differ from calculated peak sun hours, because for the latter, early sun, peak sun, and late sun irradiance is averaged. While peak sun may be an hour or less, calculated peak sun may be equivalent to 4.8 peak sun hours [8]. The pyranometer and Ohio Semitronics transducers collected data each minute and was recorded by the Campbell Scientific data logger.

The second set of data collected was diffuse radiation, solar radiation that is scattered by the atmosphere and clouds [8]. A second Huksafluxpyranometer measured daily diffuse irradiation. The third set of data was the plane of aperture using a Huksafluxpyrheliometer, which is pointed directly at the sun to measure energy.

Data were collected from November 17, 2011 through April 20, 2012. The electrical output of each series of modules, irradiance, horizontal diffuse irradiance and Plane of Aperture (POA) total irradiance were measured every minute over the course of each trial period. The trial durations were designed for a minimum of two weeks to minimize the effects of varying weather upon trial results. Data was compiled and characterized by geometry 
and reflective material used to determine efficiency (either increased or decreased) of the modules. Binned data was analyzed to compare direct beam irradiance, diffuse beam irradiance, plane of aperture irradiance, and direct beam fraction to insure the climatic conditions were similar for each series.

The data were captured at one-minute intervals during each trial period using a Campbell Scientific CR1000 using Loggernet software. Excel spreadsheets of raw data (.txt) were converted to Excel 2010.xlxs files and merged with weather files corresponding to the same minute. Nighttime data were excluded prior to data being analyzed. Initially, the period between 8:00 a.m. and 4:00 p.m. was reviewed over all six trials. It was determined that erratic data were present prior to 10:00 a.m. and after 2:00 p.m. possibly due to shading of one or both of the arrays. A determination was made to use the timeframe of 10:00 a.m. to 2:00 p.m. since this period included un-shaded data closest to solar noon over all the trials.

\subsection{Data Compilation Sets}

The following measurements were used during this study along with an analysis of each trial.

- Direct radiation.

- Diffuse radiation.

- Plane of aperture total radiation.

- Power outputs over trial periods recorded each minute.

\subsection{Major Components Necessary to Complete the Two Systems}

The main components of equipment to perform this study included the following:

- Eight Sanyo HIT 195 Double Bifacial Modules.

- Two SMA-America Sunny Boy SB-700US Inverters.

- Two Ohio Semiconductor Transducers Model PC8-004-08X5.

- Two Square D 600 Volt DC Disconnects.

- Two Research Grade HuksafluxPyranometers and Pyrheliometer.

- Campbell Scientific CR100 Data Logger.

- Three Reflective Materials.

SMA-America, maker of the SUNNY BOY US-700 inverter, specifically states the wiring between the array and the inverter should be between \#6 and \#10. Wire sizing was determined by analyzing the system specifications and measuring the wiring run from the array to the inverter. The length of wire from the array to the inverter is less than 50 feet, and the short circuit current would not exceed five amperes. Between the inverter and the solar shed, \#12-2 was used with ground. The system was grid tied inside of the shed.

\subsection{Trial Configurations}

Varying reflective materials and geometries were purposefully used under two separate arrays in six trials. Table 1 summarizes each trial.

\begin{tabular}{|c|c|c|c|c|c|}
\hline Trials & Array Location & Period of Trials & Quantity & Geometry of Modules & Reflective Materials \\
\hline \multirow[t]{2}{*}{ Trail 1} & Upper Array & November 18-December 2 & Five-Three Wired & Flush Mount & Medium Brown Shingles \\
\hline & Lower Array & & Three & Flush Mount & Medium Brown Shingles \\
\hline \multirow[t]{2}{*}{ Trail 2} & Upper Array & December 2-December 31 & Five-Three Wired & Flush Mount & White Tiocoat/Swarco Beads \\
\hline & Lower Array & & Three & Flush Mount & White Tiocoat/Swarco Beads \\
\hline \multirow[t]{2}{*}{ Trail 3} & Upper Array & January 1-January 29 & Three & Flush Mount & White Tiocoat/Swarco Beads \\
\hline & Lower Array & & Three & Horizontal Mount & White Tiocoat/Swarco Beads \\
\hline \multirow[t]{2}{*}{ Trail 4} & Upper Array & January 30-February 22 & Three & Flush Mount & White Tiocoat/Swarco Beads \\
\hline & Lower Array & & Three & Flush Mount & White Tiocoat/Swarco Beads \\
\hline \multirow[t]{2}{*}{ Trail 5} & Upper Array & February 23-March 9 & Three & Flush Mount & Aluminum Paint \\
\hline & Lower Array & & Three & Flush Mount & White Tiocoat/Swarco Beads \\
\hline \multirow[t]{2}{*}{ Trail 6} & Upper Array & March 29-April 30 & Three & Flush Mount & Aluminum Paint \\
\hline & Lower Array & & Three & Flush Mount & Medium Brown Shingles \\
\hline
\end{tabular}




\section{Trial 1}

Objective: Determine if back side power production differs between edge shaded modules (upper array) and exposed edge modules (lower array).

A comparison was made with both the upper array and lower array operational using the asphalt shingles as the reflective material for gathering baseline data (Figure 3). The upper array had a non-functioning panel mounted on either side (five panels). The premise behind the upper array design with two inactive modules was to determine if reflectance would enter from the left and the right sides. Since the lower array did not have blockage on either side, it offered the possibility to determine the extent of reflectance entering under the array from the sides. Data for this trial were collected over a 32-day period.

\section{Trial 2}

Objective: Determine if roof coating effects back-side power production difference due to partial shading of edge shaded modules (upper array) and exposed edge modules (lower array).

The second trial was the same physical configuration for the arrays as in Trial 1, but a reflective roofing material was placed below the arrays to determine if this trial would net higher power output results as shown in Figure 4.

The upper array had a non-functioning panel mounted on either side (total of five panels). Two coats of TIOCOAT $^{\mathrm{TM}}$ (Figure 5) paint were applied to a heavy weight painter's cotton canvas tarp. SWARCO glass

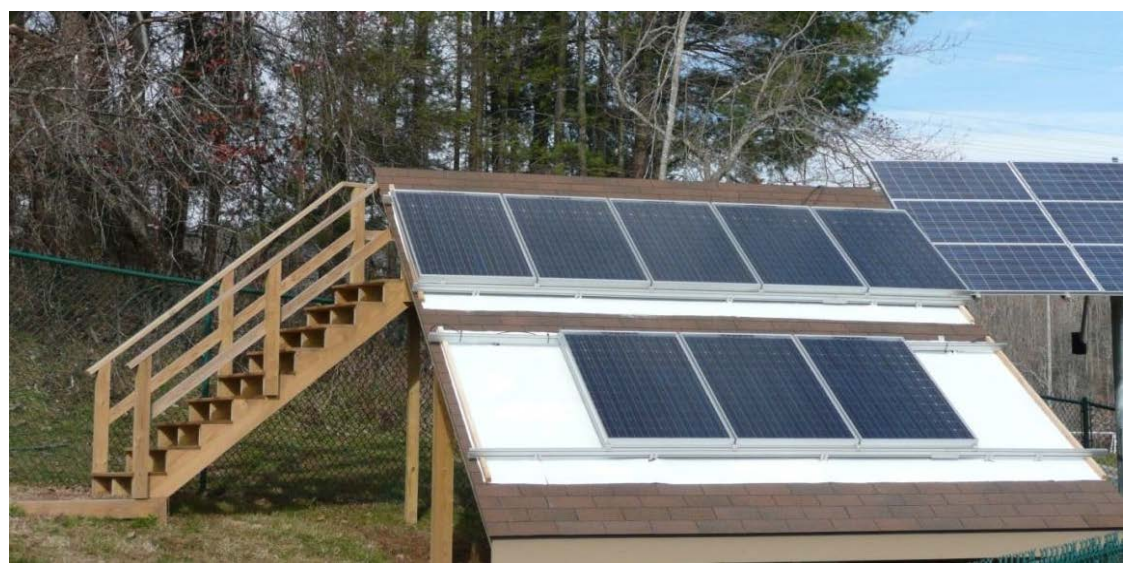

Figure 4. Photo of Trial 2. Upper array white TIOCOAT ${ }^{\mathrm{TM}}$ Flush 5 modules, lower array white TIOCOAT $^{\mathrm{TM}}$ Flush 3 modules. (Refer to Table 1 for details).

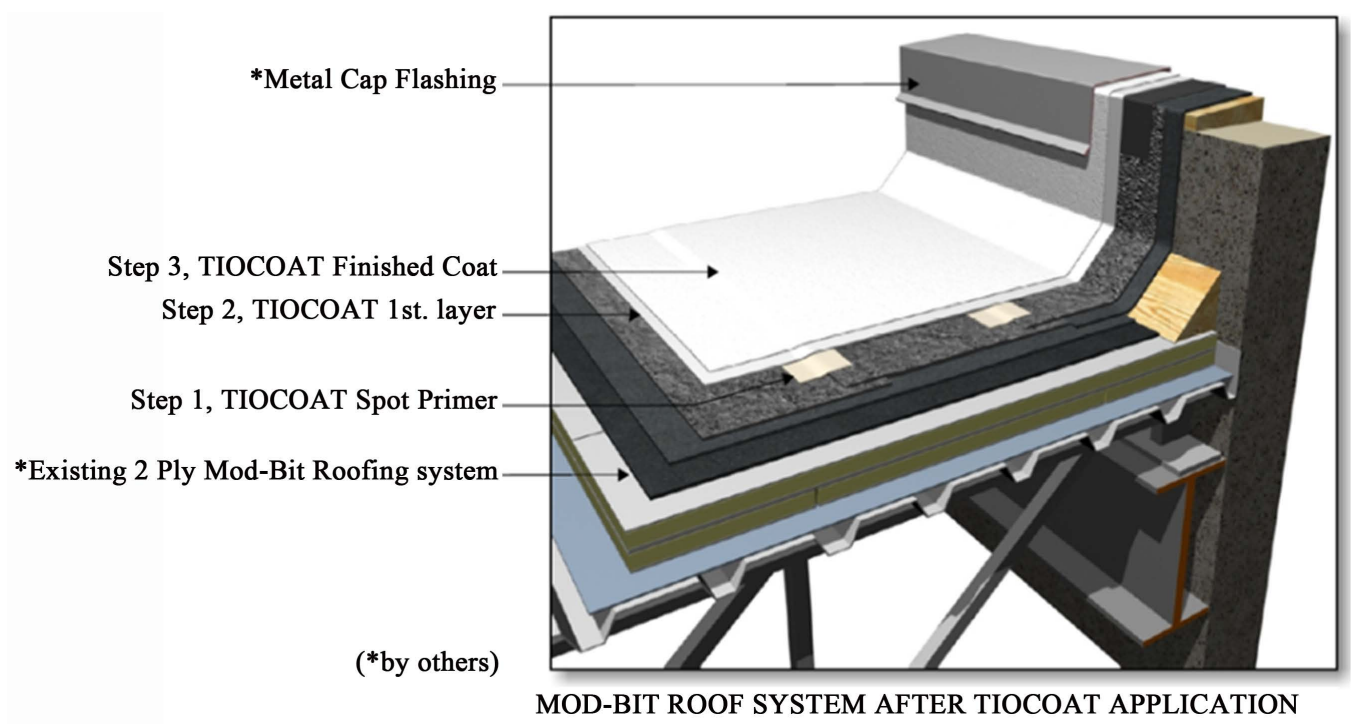

Figure 5. Diagram of TIOCOAT ${ }^{\mathrm{TM}}$ reflective white roof coating [16]. 
beads were cast onto the second application at a rate of 1.4 ounces per square foot of tarp before the last coat of TIOCOAT ${ }^{\mathrm{TM}}$ dried (Figure 6). The tarp was cut in half and placed under the two arrays. The tarp extended 8” beyond the top and bottom panel edges and 1" beyond the sides on the upper array. The lower array reflective material extended 8" above and below the array and 40" beyond the right and left panel edges on the lower array.

\section{Trial 3}

Objective: Determine the effect on power output difference due to varying panel mounting orientation.

The third trial consisted of using the same reflective material in Trial 2, but the two outer unwired modules on the upper array were removed (Figure 7). Additionally, the lower array was tilted to achieve $0^{\circ}$ or horizontal that can be regarded as canopy installations. These data helped determine whether the tilt affects the absorption of diffuse radiation by the lower surface on the lower array.

Trial 4

Objective: Verify equal power outputs with identical experimental conditions.

The configuration of Trial 4 was modified so that both upper and lower arrays were identically mounted flush to the roof, 6" above TIOCOAT ${ }^{\mathrm{TM}}$ and SWARCO glass beads (Figure 8). The objective was to attempt to verify power output was identical for both arrays.

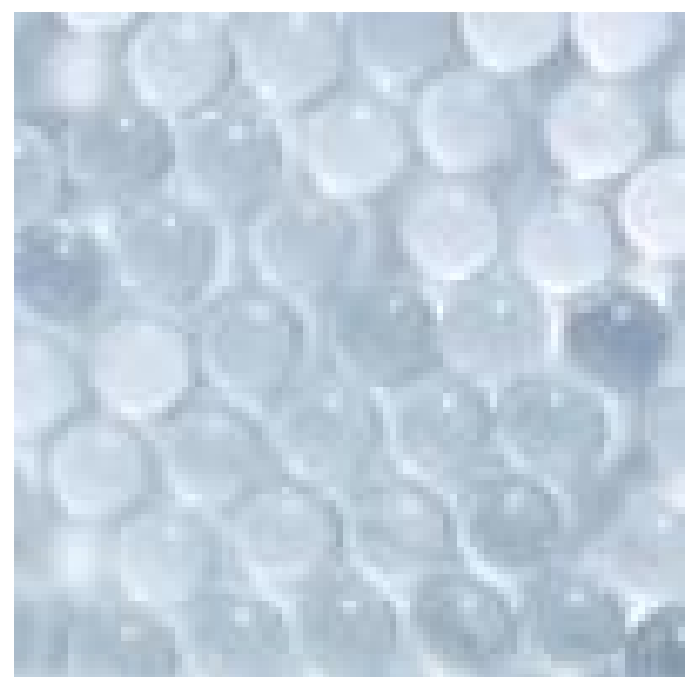

Figure 6. Microphotograph of SWARCO glass beads used to enhance reflectivity in road striping [17].

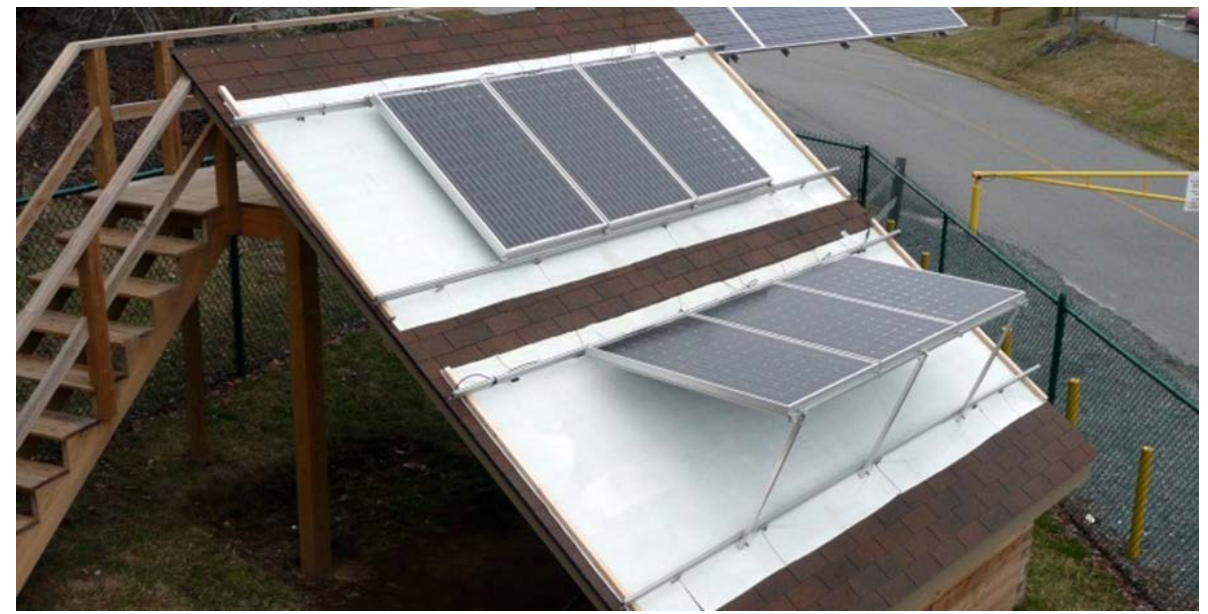

Figure 7. Photo of Trial 3. Lower array poised at horizontal. Upper array white TIOCOATTM-3 modules, lower array white TIOCOAT ${ }^{\mathrm{TM}} 3$ modules horizontal. (Refer to Table 1 for details). 


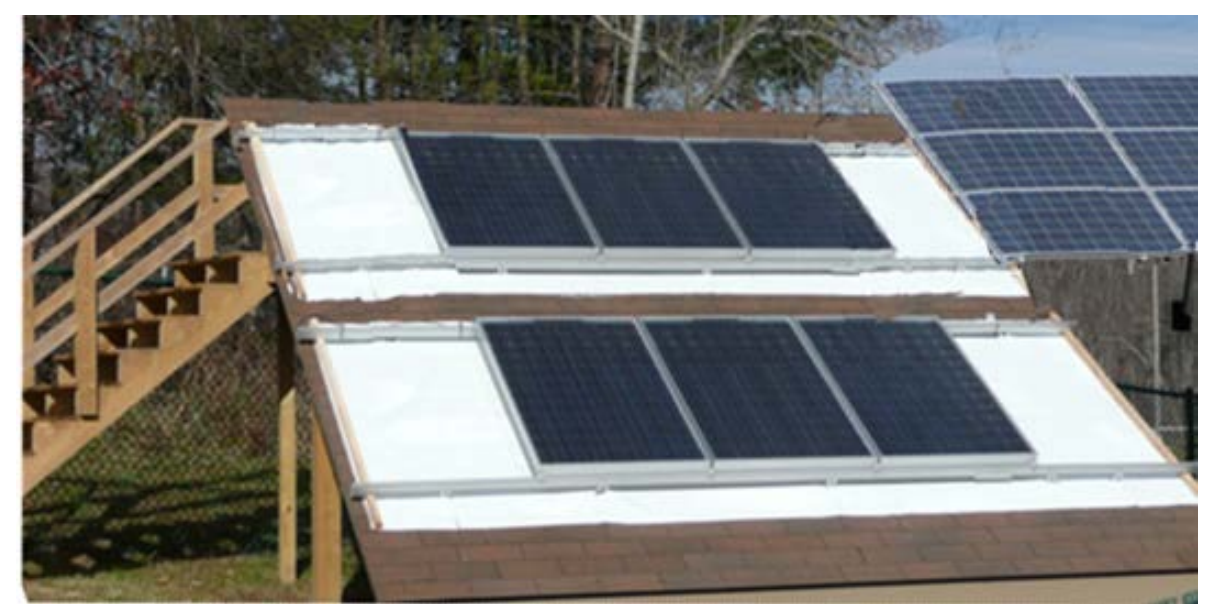

Figure 8. Photo of Trial 4. Upper array white TIOCOATTM flush 3 modules, lower array white TIOCOAT $^{\text {TM }}$ flush 3 modules. (Refer to Table 1 for details).

\section{Trial 5}

Objective: Determine the power output difference from differing reflective coatings below the arrays.

Three coats of Benjamin Moore ${ }^{\circledR}$ Weatherproof Aluminum Paint were applied to a canvas tarp that covered the roof shingles. The tarp extended 8 inches beyond the top and bottom panel edges and 40" beyond the right and left panel edges (Figure 9).

Trial 6

Objective: Determine the power output difference from a reflective surface vs. a non-reflective surface below the arrays.

Trial 6 had the same module configuration of three modules flush per array, the upper array utilized Benjamin Moore silver roof paint as the reflective material, and the lower array utilized medium brown shingles as the reflective material (Figure 10).

\section{Results}

This section describes the average power differences between the two arrays (1) in each of the six trials.

$$
\text { Average Power Difference }=\sum_{i=1}^{n} \frac{X_{i}-Y_{i}}{\text { Average of } X_{i} \text { and } Y_{i}} \div n \times 100
$$

(X: Power Output of Upper Array (Watt/ Minute), and Y: Power Output of Lower Array (Watt/ Minute)).

\section{Trial 1}

Figure 11 indicates very little power difference with a nearly identical graph for both arrays, where their power outputs varied from $353.53 \mathrm{~W}$ to $516.61 \mathrm{~W}$. Although the lower array consistently performed better than the upper array, the average the power difference between the two arrays (upper-lower) was only $-0.24 \%(s=$ $1.57 \%, n=1963)$. Using the two additional modules over medium brown shingles to create purposeful shading on either side of the upper array caused little difference in power output.

\section{Trial 2}

The average power difference between the two arrays was $0.42 \%(s=7.76 \%, n=4920)$, which suggests that using the two additional modules over the surface of a TIOCOAT ${ }^{\mathrm{TM}}$ and SWARCO glass bead configuration to create purposeful shading on either side of the upper array caused little difference in power output. As for the power output, the upper array ranged from 362.72 to 456.77 and the lower array ranged from 318.13 and 460.68 , as shown in Figure 12.

\section{Trial 3}

The power output of the upper array varied from 308.96 to 518.88. In contrast, the power output of the lower array, which was poised at $0^{\circ}$ or $36^{\circ}$ relative to the reflective surface for use in overhead canopies, was drastically reduced, ranging from 239.48 and 356.62. The upper array has a consistently higher percentage of power difference in comparison to the lower array (Figure 13). The average power difference between the two arrays 


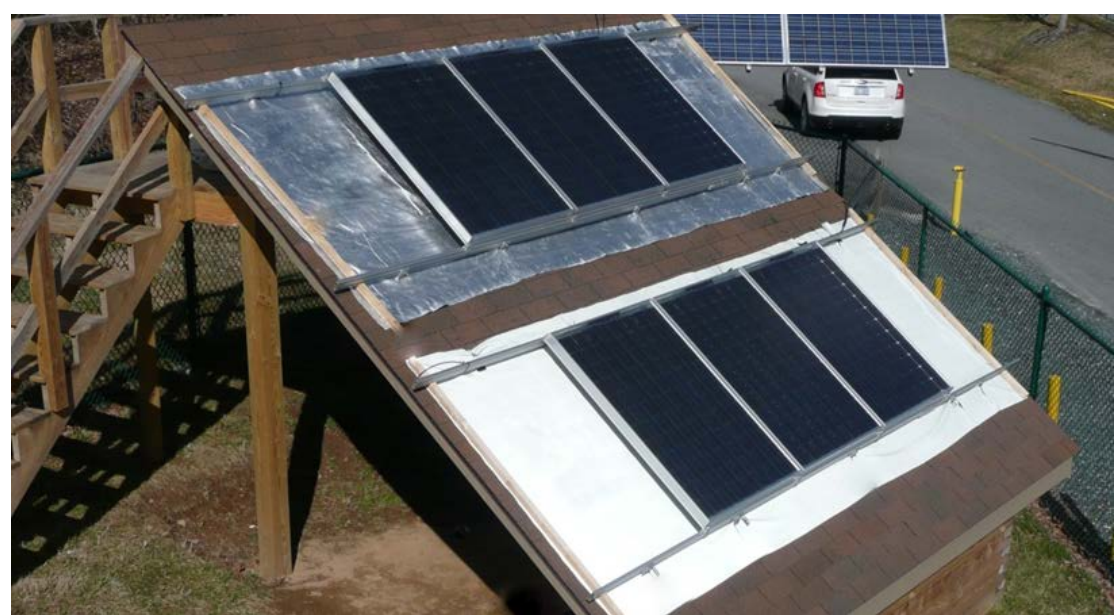

Figure 9. Photo of Trial 5. Upper array silver roof paint flush 3 modules, lower array white TIOCOAT ${ }^{\mathrm{TM}}$ flush 3 modules. (Refer to Table 1 for details).

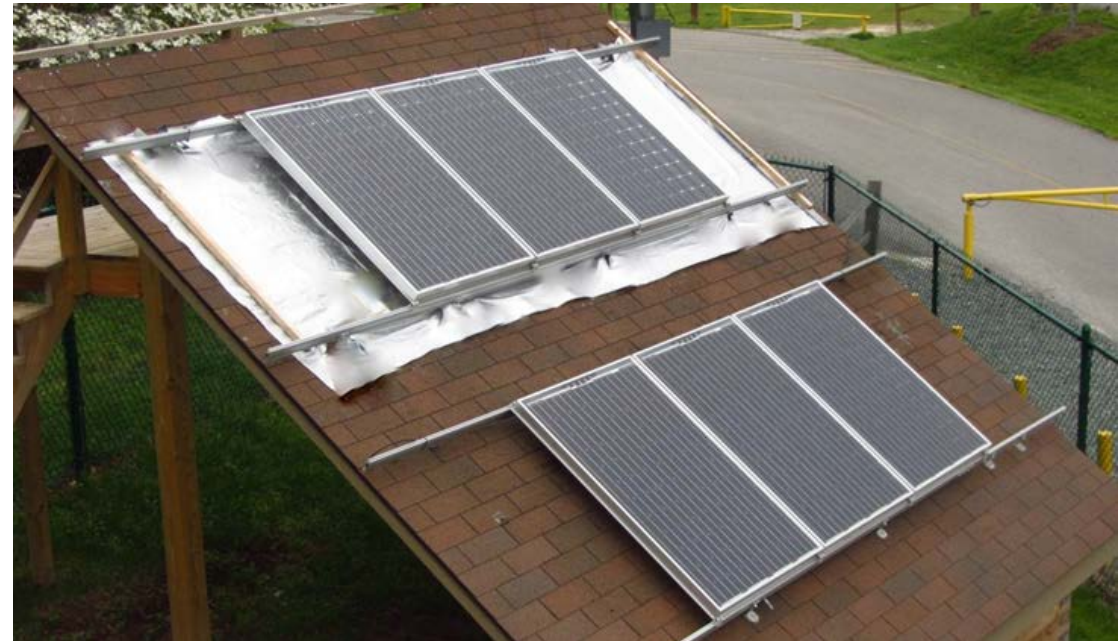

Figure 10. Photo of Trial 6. Upper array silver roof paint flush 3 modules, lower array shingles flush 3 modules. (Refer to Table 1 for details)

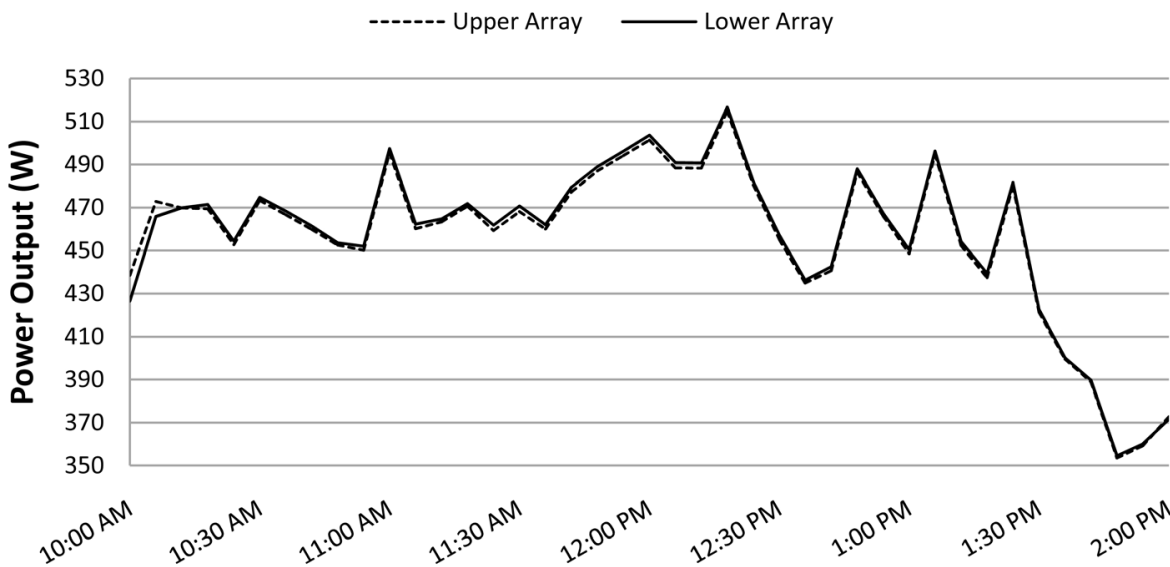

\section{Time of Day (hours)}

Figure 11. Chart of Trial 1. Power output vs. time of day. 


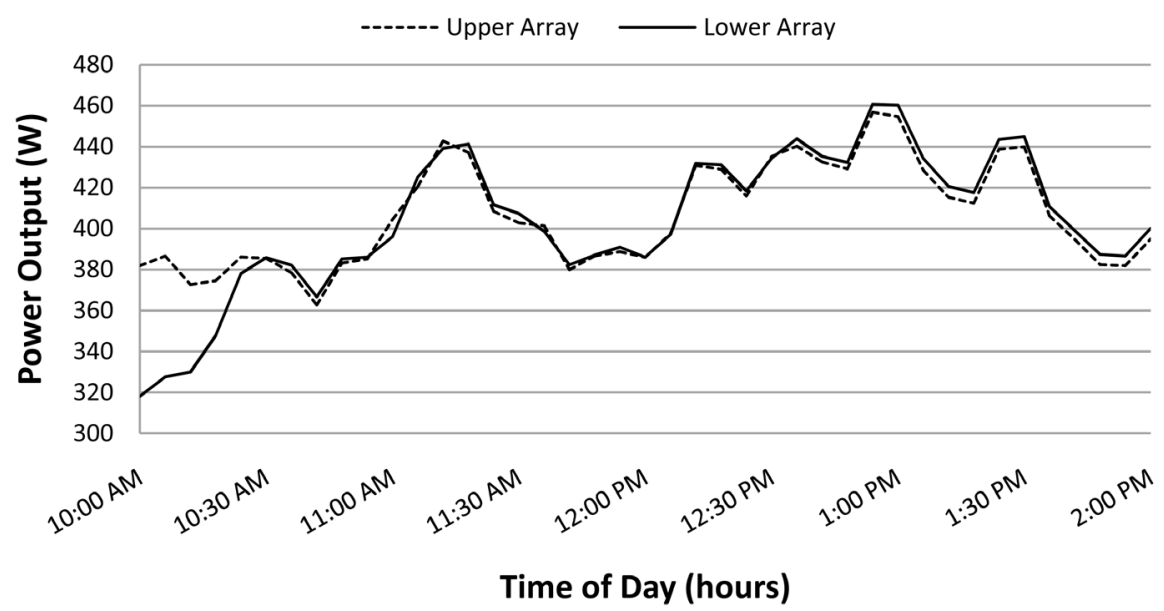

Figure 12. Chart of Trial 2. Power output vs. time of day.

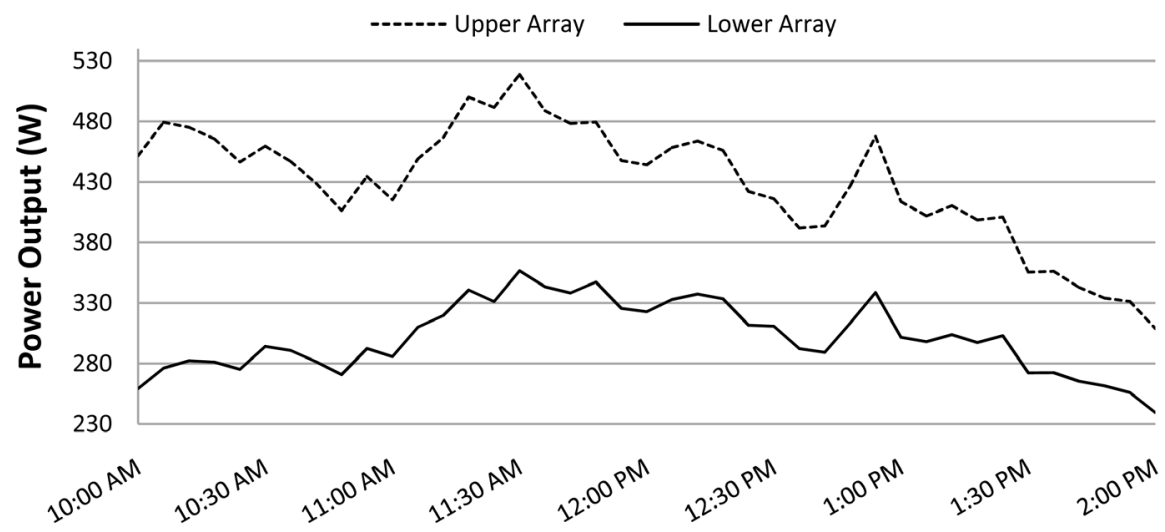

Time of Day (hours)

Figure 13. Chart of Trial 3. Power output vs. time of day.

was $29.3 \%(s=23.63 \%, n=4450)$. This horizontal positioning clearly limits the production of power, at least in this configuration, in this location, during this trial.

\section{Trial 4}

As shown in Figure 14, the power output was nearly identical with minimal variation between the arrays, ranging from 381.49 to 511.91 . The average power difference was $1.00 \%(s=6.61 \%, n=3782)$.

This trial was performed as a form of verification that both arrays would perform identically by using the same reflective material, same equipment, and the same time period. The attempt was to measure a difference in power of zero, but the trial actually netted a power difference of $1.00 \%$. The result of this trial signifies that within all trials, there is a minimum $1.00 \%$ margin of error which indicates the difference in power must be greater than $1.00 \%$ to be considered greater that zero.

Trial 5

The upper array slightly outperformed the lower array before 1:30 pm (Figure 15) but overall the average power difference between the arrays was just $0.68 \%(s=8.49 \%, n=3017)$. The power output for both arrays varied from 349.30 to 467.08. A reflective roofing surface with three coats of Benjamin Moore ${ }^{\circledR}$ Weatherproof Aluminum Paint at the upper array had little effect on the power output compared to a reflective surface with TIOCOAT $^{\mathrm{TM}}$ and SWARCO glass bead at the lower array.

\section{Trial 6}

With power varying between 389.26 and 543.72, the upper array consistently outperformed the lower array as shown in Figure 16. The average power difference was $2.79 \%(s=2.88 \%, n=4764$. The results indicate that in fact, the reflective silver material did increase power over the medium brown shingles. 


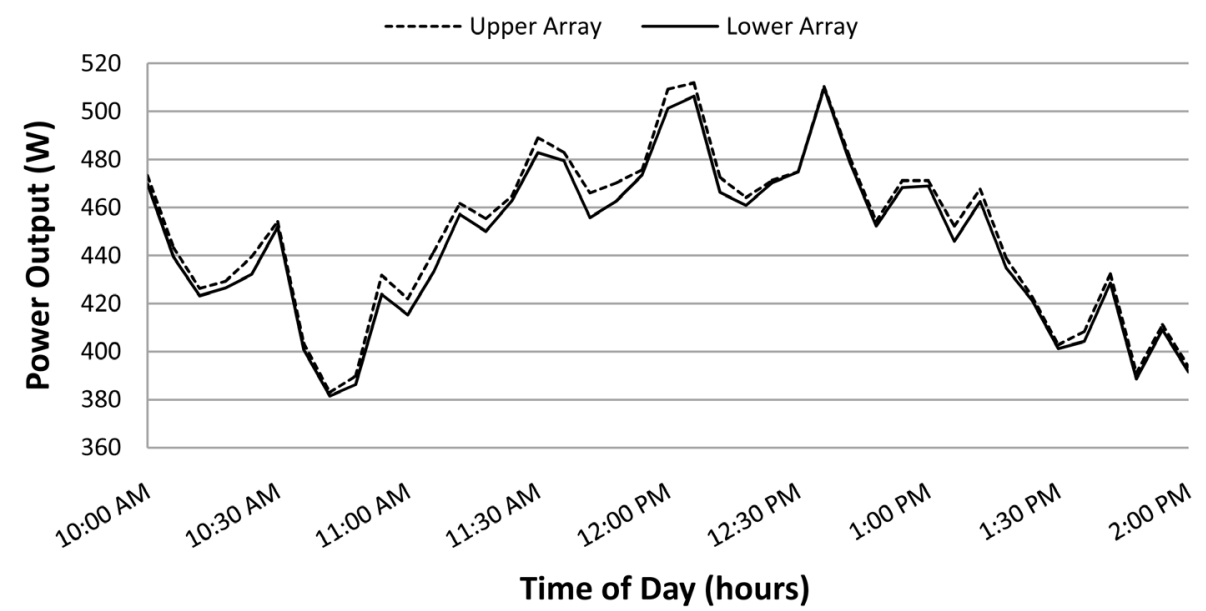

Figure 14. Chart of Trial 4. Power output vs. time of day.

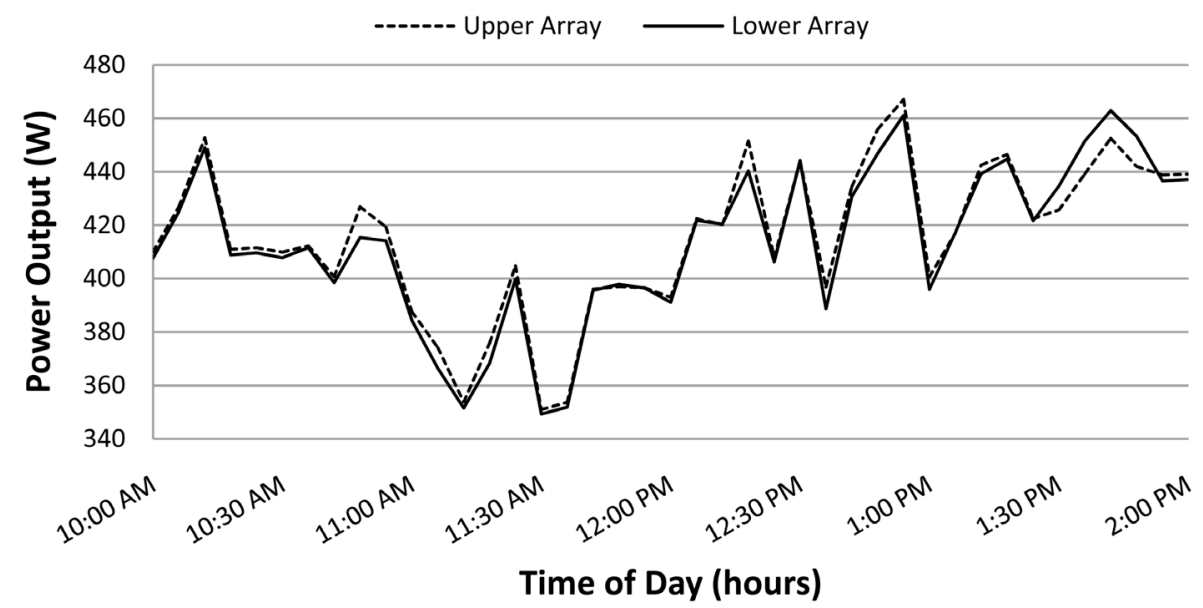

Figure 15. Chart of Trial 5. Power output vs. time of day.

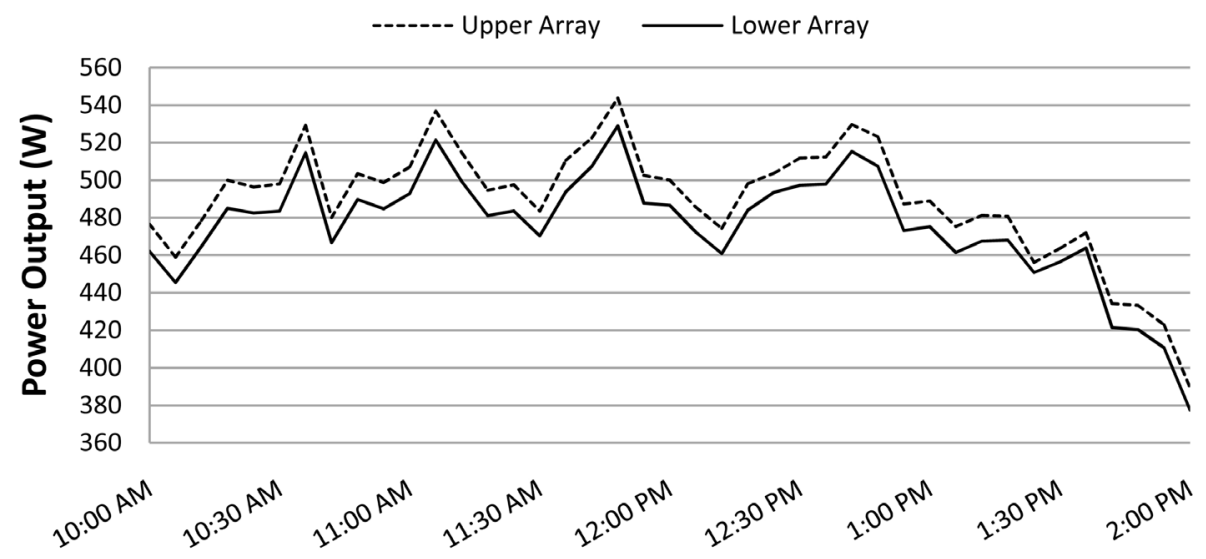

Time of Day (hours)

Figure 16. Chart of Trial 6. Power output vs. time of day.

\section{Discussions and Conclusions}

This study examined how different configurations would impact the power output generated from bifacial mod- 
ules. Varying reflective materials and geometries were purposefully used under two separate arrays with three basic reflective geometries and three different panel installation geometries in six trials in the same location for a period of nearly five months. The study was conducted between late fall 2011 and early spring 2012 with a fairly typical winter for the Boone, North Carolina location. The arrays may have performed differently during summer months when the sun angle is higher accounting for the differences in actual panel output versus rated output.

\subsection{Reflective Materials}

Overall, varying different reflective materials below the lower surface of the modules did little to increase power. It is conceivable to conclude that there is a possibility of increasing power by altering reflective material below the modules, but numerous variables such as array location, module distance from reflecting surface, geographic location, and maintenance of the arrays would be a few determining factors whether this escalation in power could be duplicated or possibly increased by careful planning.

\subsection{Edge Placement}

In Trial 1 and Trial 2, the upper array side edges were shaded with non-working modules. In these two trials, the reflective material extended all the way to the left and right of the unconnected modules on the upper array which physically had 5 modules. The reflective material for the lower array was the same size, but because there were on three modules in this array, the material extended 40.5 inches on either side of the left and right lower array of three modules. Reflective material was under all of modules throughout the entire study, and by visual inspection, the area under the non-working modules was not as exposed to as much light as the lower configuration with exposed edges. This configuration of unconnected side modules on the upper array in Trial 1 produced no difference in power, but in Trial 2, the lower array outperformed the upper array, but the overall power difference remained close to zero percent. Further, varying different reflective materials below the lower surface of the modules did little to increase power.

\subsection{Module Geometry}

Trial 3 geometry compared two geometries (upper array flush vs. lower array horizontal) to determine the effect of module placement both from a performance standpoint, as well as a practical application in the field. In this trial, the lower array racking was modified to raise the array to a horizontal position. Two vital aspects of this trial are important, the first being the actual geometry, and the second being the fact that the horizontal array had the reflective material at a $36^{\circ}$ angle from the bottom of the array. An assumption could be made that the upper array was receiving direct and diffuse irradiation, but the lower array was receiving more diffuse irradiation and less direct irradiation due to the array's angle. Test results were astounding with the difference in geometry. Altered geometry had the greatest effect on power output with the flush array outperforming the horizontal array. Trial 3 results indicated that with the lower array of Sanyo bifacial modules mounted horizontally, power was drastically reduced by nearly $40 \%$ compared to the upper array that was mounted at $36^{\circ}$ relative to horizontal and flush to the roof. It is possible to conclude that with horizontal placement of the bifacial arrays in this application, it was not the best geometric configuration to increase power output. The best position for a photovoltaic module is perpendicular to the sun's rays to absorb maximum irradiation.

\subsection{Applications}

Using bifacial modules solely for the purpose of increasing power with the ability to use fewer modules is an unwise investment, based upon the findings in this study. But, the use of these semi-translucent modules should be considered an opportunity to produce power within architectural applications not previously realized. The modules may also be used in ballasted mounts on a flat roof as well as in combination with a reflective roof surface such as TIOCOAT ${ }^{\mathrm{TM}}$; however array geometry is vital in all types of installation.

\subsection{Systematic Uncertainty}

To estimate the experimental systematic uncertainty, a trial was conducted (Trial 4) in which two nominally identical arrays were monitored. During this trial the mean of the distribution of percent power difference was 
$1 \%$. This systematic uncertainty dominates the statistical uncertainty; therefore, an overall uncertainty of $1 \%$ will be applied to all percent power differences. In other words, there is a minimum $1 \%$ margin of error which indicates that the difference in power must be greater than $1 \%$ to be considered greater than zero.

\subsection{Limitation of the Study}

This study was conducted in Boone, NC at the Appalachian State University. While using one location for a study is not optimal, results may be suggested in other locations by use of National Renewable Energy Laboratory (NREL) data. Only Sanyo HIT 195 Bifacial Modules were used due to the limited number of manufacturers of these types of panels. Two series of three modules each were configured. Since the lower portion of the bifacial module is light absorptive, control series of modules were tested with standard asphalt shingles. Using one inverter for three modules created an additional challenge. If a portion of one module surface becomes blocked or shaded, performance of the complete series of three modules may be reduced. Shading will always inhibit direct irradiance absorbance and will reduce the output of modules as well as the arrays to which they are wired. While shading can be difficult to avoid, every attempt was made to keep shading to a minimum. As the position of the sun changes over time, the location of the shadows on the reflective surfaces created by the module mounts will also change.

\subsection{Significance of the Study}

The results of the study may be useful to the manufacturer by enhancing the marketability of bifacial photovoltaic modules for many different rooftop applications where a canopy or facade may not be available or practical. The study may benefit the end user since the bifacial modules may be installed on a pitched rooftop of a residence or business. This study also provided an independent examination of actual performance as it relates to the manufacturer's specifications showing that panel geographical locations will affect power output.

Additionally, a recorded power increase may serve as useful data to Appalachian State University, Department of Technology and Environmental Design, and the Sanyo Electric Corporation, as well as help modify future installations to net the highest power output of these modules.

\section{References}

[1] Sanyo HIT Products (2010). http://us.sanyo.com/Consumer-Solar/HIT-Double

[2] Green, M.A., Emery, K., Hishikawa, Y., Warta, W. and Dunlop, E.D. (2015) Solar Cell Efficiency Tables (Version 45). Progress in Photovoltaics: Research and Applications, 23, 1-9. http://dx.doi.org/10.1002/pip.2573

[3] Bifacial Photovoltaic Module: HIT Double 195 [Specifications Sheet] (2010). http://us.sanyo.com/Dynamic/DocumentsManager/Solar\%20Consumer/HIT\%20Double\%20195\%20w_042010.pdf

[4] Fowles, A. (2012) SANYO HIT ${ }^{\circledR}$ Solar Modules to Become "Panasonic HIT ${ }^{\circledR}$ ". http://www.pv-magazine.com/news/details/beitrag/sanyo-hit-modules-become-panasonic_100005226/\#axzz40m4XM $\underline{\mathrm{mAc}}$

[5] Solar Power (Solar Cells) The Components of a Solar Cell (2011). http://library.thinkquest.org/04apr/00215/energy/solar/solar_cells.htm

[6] Photovoltaic Panel or Module Construction (2012). http://www.solar-facts.com/panels/panel-construction.php

[7] Zhao, L., Zhou, C.L., Li, H.L., Diao, H.W. and Wang, W.J. (2008) Design Optimization of Bifacial HIT Solar Cells on P-Type Silicon Substrates by Simulation. Solar Energy Materials and Solar Cells, 92, 673-681. http://dx.doi.org/10.1016/j.solmat.2008.01.018

[8] Dunlop, J.P. (2010) Photovoltaic Systems. 3rd Edition, American Technical Publishers, Inc., Orland Park.

[9] Poulek, V., Khudysh, A. and Libra, M. (2015) Innovative Low Concentration PV Systems with Bifacial Solar Panels. Solar Energy, 120, 113-116. http://dx.doi.org/10.1016/j.solener.2015.05.049

[10] Cuevas, A., Luque, A., Eguren, J. and Delalamo, J. (1982) 50-Percent More Output Power From an Albedo-Collecting Flat Panel Using Bifacial Solar-Cells. Solar Energy, 29, 419-420. http://dx.doi.org/10.1016/0038-092X(82)90078-0

[11] Untila, G.G., Kost, T.N., Chebotareva, A.B., Zaks, M.B., Sitnikov, A.M. and Solodukha, O.I. (2005) A New Type of High-Efficiency Bifacial Silicon Solar Cell with External Busbars and a Current-Collecting Wire Grid. Semiconductors, 39, 1346-1351. http://dx.doi.org/10.1134/1.2128464

[12] Robles-Ocampo, B., Ruiz-Vasquez, E., Canseco-Sanchez, H., Cornejo-Meza, R.C., Trapaga-Martinez, G., Garcia-Ro- 
driguez, F.J. and Vorobiev, Y.V. (2007) Photovoltaic/Thermal Solar Hybrid System with Bifacial PV Module and Transparent Plane Collector. Solar Energy Materials and Solar Cells, 91, 1966-1971.

http://dx.doi.org/10.1016/j.solmat.2007.08.005

[13] Fowles, A. (2010) Sanyo Solar Canopies Give Atlanta Architects \& Building Owners Something to Smile About-Tax Day, Earth Day and Every Day. http://www.prweb.com/releases/SANYO/solar_canopy/prweb3941394.htm

[14] Sanyo Bifacial Panels-A New Approach to Extracting More Energy from Your Rooftop (2011). http://www.solartown.com/learning/solar-panels/sanyo-bifacial-solar-panels-a-new-approach-to-extracting-more-energ y-from-your-rooftop/

[15] Hezel, R. (2003) Novel Applications of Bifacial Solar Cells. Progress in Photovoltaics, 11, 549-556. http://dx.doi.org/10.1002/pip.510

[16] TIOCOAT ${ }^{\mathrm{TM}}$ Reflective White Roof Coating (2011). http://tiocoat.com/

[17] Standard Glass Bead Products (2012).

http://www.swarco.com/en/Products-Services/Traffic-Materials/Glass-Beads/Standard-glass-bead-products 